\title{
Article \\ Study on Black Phosphorus Characteristics Using a Two-Step Thinning Method
}

\author{
Qin Lu ${ }^{1, *}$, Xiaoyang Li $^{1}$, Haifeng Chen ${ }^{1}$, Yifan Jia ${ }^{1}{ }^{\mathbb{D}}$, Tengfei Liu ${ }^{1}$, Xiangtai Liu ${ }^{1}$, Shaoqing Wang ${ }^{1}$, Jiao Fu ${ }^{1, *}$,
} Daming Chen ${ }^{2}{ }^{\mathbb{D}}$, Jincheng Zhang ${ }^{3}$ and Yue Hao ${ }^{3}$

Citation: Lu, Q.; Li, X.; Chen, H.; Jia, Y.; Liu, T.; Liu, X.; Wang, S.; Fu, J.; Chen, D.; Zhang, J.; et al. Study on Black Phosphorus Characteristics Using a Two-Step Thinning Method. Materials 2022, 15, 615. https:// doi.org/10.3390/ma15020615

Academic Editors: Lukáš Richtera and Vojtěch Adam

Received: 26 November 2021

Accepted: 11 January 2022

Published: 14 January 2022

Publisher's Note: MDPI stays neutral with regard to jurisdictional claims in published maps and institutional affiliations.

Copyright: (c) 2022 by the authors. Licensee MDPI, Basel, Switzerland. This article is an open access article distributed under the terms and conditions of the Creative Commons Attribution (CC BY) license (https:// creativecommons.org/licenses/by/ $4.0 /)$.
1 Key Laboratory of Advanced Semiconductor Devices and Materials, School of Electronic Engineering, Xi'an University of Posts \& Telecommunications, Xi'an 710121, China; 1xy974613873@sina.com (X.L.); chenhaifeng@xupt.edu.cn (H.C.); jiayifan@xupt.edu.cn (Y.J.); 1tf001123@163.com (T.L.); liuxiangtai.1990@163.com (X.L.); wsqing1212@163.com (S.W.)

2 Departamento de Ingeniería Mecánica, Universidad de Santiago de Chile, Santiago 9160000, Chile; daming.chen@usach.cl

3 Key Laboratory for Wide Band Gap Semiconductor Materials and Devices of Education, School of Microelectronics, Xidian University, Xi'an 710071, China; jchzhang@xidian.edu.cn (J.Z.); yhao@xidian.edu.cn (Y.H.)

* Correspondence: luqin@xupt.edu.cn (Q.L.); jiao_fu@foxmail.com (J.F.)

\begin{abstract}
A mild two-step method of black phosphorus (BP) flake thinning was demonstrated in this article. Slight ultraviolet-ozone (UVO) radiation followed by an argon plasma treatment was employed to oxidize mechanically exfoliated BP flakes and remove the surface remains of previous ozone treatment. The annealing process introduced aims to reduce impurities and defects. Low damage and efficient electronic devices were fabricated in terms of controlling the thickness of BP flakes through this method. These results lead to an important step toward the fabrication of high-performance devices based on two-dimensioned materials.
\end{abstract}

Keywords: black phosphorus; mechanical exfoliation; ultraviolet radiation; annealing; field-effect transistor

\section{Introduction}

Among 2D materials, black phosphorus (BP) exhibits a range of properties, such as a thickness-dependent bandgap [1,2], high carrier mobility [3], and extraordinary thermoelectric properties [4]. Various reports have shown the exceptional optical properties, optoelectronic properties, and biomedical performance of BP devices [5-10], which makes it a potential candidate for next-generation materials. However, the lack of a bottom-up approach for film fabrication limits its practical applications, and issues of the degradation of BP for applying a designed thickness to form high-quality surfaces have been investigated. Wet chemical and thermal treatment require not only controlling the thickness of BP flake but also maintaining its stability [11,12]. Conductive atomic force microscope anodic oxidation and electron beam sculpting were reported to accomplish nanopatterning and layer-by-layer thinning of BP [13,14]. Thermal oxidization [15,16] and plasma [17-19] treatment are established, commonly used thinning processes. Although using one of these thinning processes alone can thin down BP flakes, the residual oxidation products from oxidization and the non-uniformity of plasma dry thinning should be considered. Among these methods, UVO has displayed both low cost and easy control [20,21]. The oxide layer induced by UVO formed to form on the BP surface makes it more stable than that in ambient conditions but influences the electronic performance of devices.

To prevent this problem, we introduce in this work an effective, mild two-step method using black phosphorus (BP) flakes to form uniform and thin BP. BP flakes were first exposed to slight UVO radiation for a few minutes, and a mild argon plasma treatment followed. Steps were taken to reduce the impurities and defects from thinning through an 
annealing process in a $\mathrm{N}_{2}$ atmosphere. By controlling the UVO radiation, a stable thinning rate of exfoliated BP flakes was achieved. The residual oxidation products created from UVO can be easily removed by light plasma, and the defects induced during this process can be improved by the subsequent annealing process. Through the material surface roughness analysis, flattening surface was obtained through this two-step technique. Moreover, the performance of the BP field-effect transistor (FET) fabricated improved significantly.

\section{Experimental Section}

Materials and Methods

Figure 1 shows a schematic diagram of the thinning process of the BP flakes. BP flakes were obtained by mechanical exfoliation from a bulk BP crystal by Scotch tape, and following this, they were transferred directionally to source and drain electrodes $(\mathrm{Ti} / \mathrm{Au}$ $5 \mathrm{~nm} / 50 \mathrm{~nm}$ ) which was on a $285 \mathrm{~nm} \mathrm{SiO} 2 / \mathrm{Si}$ substrate. To gain the target thickness, BP flakes were exposed to slight UVO through ultraviolet-ozone cleaning (SC-UV-I) equipment. Controlling the time of exposure to UVO light radiation $(50 \mathrm{~W})$ resulted in a thinning rate of about $2 \mathrm{~nm} / \mathrm{min}$. In this process, only the chemical reaction induced by the ozone oxidation can thin down the BP flakes without direct bombardment. Following this, light Ar atmosphere plasma was introduced using reactive ion etching (RIE) equipment to remove the residue on the top surface of the BP. After that, a $300{ }^{\circ} \mathrm{C}$ annealing process was used to repair and reduce the interface defects. The thickness and roughness of the flakes were measured by a Cypher $S$ atomic force microscope (AFM) in tapping mode. Raman spectra characteristics were gathered using a LabRAM HR Raman spectrometer with an excitation wavelength of $514 \mathrm{~nm}$. X-ray photoelectric spectroscopy (XPS) was used to analyze the binding energies of the BP flakes. The device's electrical measurements were performed using an Agilent B1500A semiconductor parameter analyzer under vacuum conditions.

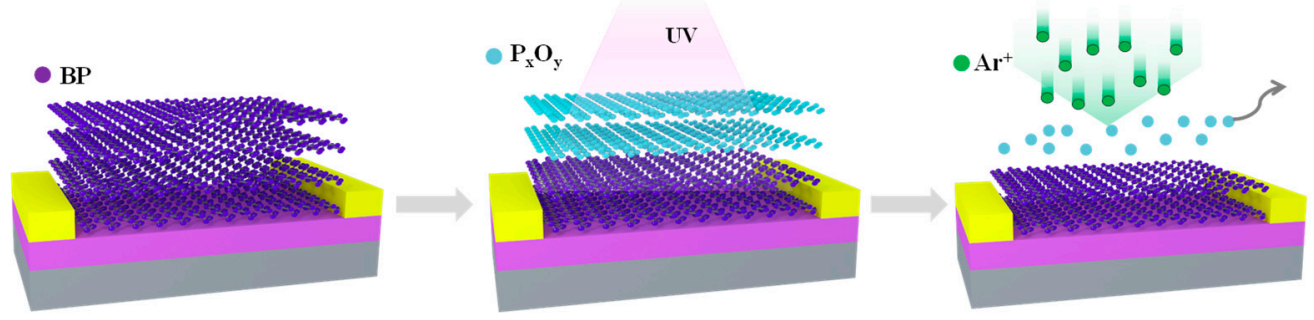

Figure 1. Schematic diagram of thinning process of the BP flakes. Slight UVO radiation was introduced to oxidize the BP flakes, and Ar plasma was used to remove the residue.

\section{Results and Discussion}

\subsection{Material Characteristics}

Figure 2a,d show the optical microscopy images of the exfoliated BP flakes before and after light UV thinning and Ar treatment, respectively. The surface morphology and thickness were monitored by AFM, as shown in Figure 2b,c,e,f. Although the samples were vacuum-packed after experiments to avoid degradation, there were some small bubbles observed in the BP surface in optical microscopy images, shown in Figure $2 b$, which is due to airborne $\mathrm{H}_{2} \mathrm{O}$ and $\mathrm{O}_{2}$ during optical microscopy observation [22,23], and bubbles formed again more obviously during AFM measurements, shown in Figure 2e. Then, the BP sample was annealed in a $\mathrm{N}_{2}$ atmosphere for $1 \mathrm{~min}$ at $300{ }^{\circ} \mathrm{C}$. The resultant sample, presented in Figure $2 \mathrm{f}$, was measured to be $\sim 8 \mathrm{~nm}$ thick by AFM, compared with the thickness of $\sim 13 \mathrm{~nm}$ before thinning shown in Figure 2c. Meanwhile, the measured surface roughness of the thinned BP flakes is $1.76 \mathrm{~nm}$, compared with $1.73 \mathrm{~nm}$ before thinning, indicating little change in the surface. Since the AFM characterization was performed after the Raman characterization and a high power of laser was used during the Raman test, this results in the broken point in the surface of the BP flakes in Figure 2e. 

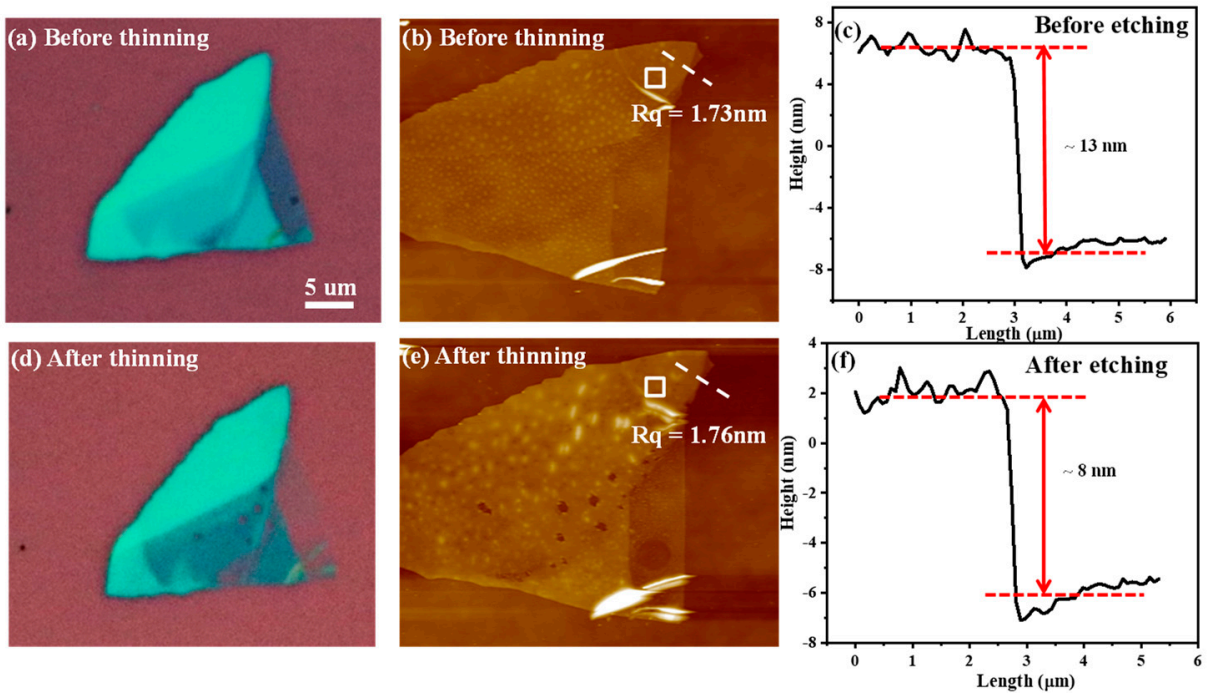

Figure 2. (a,b) Optical microscope and AFM image of BP flakes before thinning with a roughness of $1.73 \mathrm{~nm}$ at the square. (c) The thickness of the flake, which is $-13 \mathrm{~nm}$ corresponding to the dotted line in $(\mathbf{b}, \mathbf{d}, \mathbf{e})$, which are optical microscope and AFM images of BP flakes after thinning with a roughness of $1.76 \mathrm{~nm}$ at the square. (f) The thickness of the flake, which is $-8 \mathrm{~nm}$ corresponding to the dotted line in (e).

The optical properties of the UVO and plasma-treated BP flakes were investigated using Raman spectroscopy. Figure $3 \mathrm{a}-\mathrm{h}$ shows an optical microscopy image as a function of light UVO exposure time. With the increasing exposure time, the BP flakes decreased from $14 \mathrm{~nm}$, and the thinning rate was about $2 \mathrm{~nm} / \mathrm{min}$, confirmed by AFM. Color and thickness of BP provide an effective method of monitoring the BP thickness during the thinning process. Figure $3 i$ shows Raman spectra of the samples with varying light UVO exposure times, which corresponds to Figure $3 \mathrm{a}-\mathrm{g}$. In these spectra, three prominent peaks due to vibrations of the crystalline lattice matching the Raman shifts attributed to the $\mathrm{A}^{1} \mathrm{~g}$ (out-of-plane vibrations), $\mathrm{B}_{2 \mathrm{~g}}$, and $\mathrm{A}^{2} \mathrm{~g}$ (in-plane vibrations) phonon modes of $\mathrm{BP}$ are located at $360.7,437.4$, and $465.6 \mathrm{~cm}^{-1}$, respectively. The spectra are normalized to the Raman peak of the $\mathrm{A}^{2}$ g peak at $465.6 \mathrm{~cm}^{-1}$ and indicate the retained crystalline structures of BP after UVO light and plasma treatment $[24,25]$. The peak intensities of all three phonon modes decreased, while the Raman peak of Si increased with increasing exposure time, which can also be seen through the ratio of the intensities of the $\mathrm{A}^{1}{ }_{\mathrm{g}}, \mathrm{A}^{2}{ }_{\mathrm{g}}$, and Si peak, respectively. In Figure $3 \mathrm{j}$, both peak ratios of $\mathrm{A}_{\mathrm{g}}^{1} / \mathrm{Si}$ and $\mathrm{A}_{\mathrm{g}}^{2} / \mathrm{Si}$ used as a gauge decreased after longer exposure processes, indicating the thinning of the BP flakes $[19,25]$.

Figure 4 displays the chemical bonding information on an element of the BP flake before and after treatment by X-ray photoemission spectroscopy (XPS). Survey XPS spectrum of BP flakes was shown in Figure S1. All the data are calibrated with the $C 1$ s peak, which is recorded as constant binding energy of $284.6 \pm 0.2 \mathrm{eV}$ from the adventitious carbon. Before thinning treatment, the decomposition of the P element into two peaks was located to $\sim 129.9$ and $130.8 \mathrm{eV}$, assignable to $2 \mathrm{p}_{3 / 2}$ and $2 \mathrm{p}_{1 / 2}$ binding energy, respectively, shown in Figure 4a. The broadband located at $\sim 134 \mathrm{eV}$ is regarded as the contribution to BP oxidation during the treatment process, including P-O-P, $\mathrm{O}-\mathrm{P}=\mathrm{O}$, and $\mathrm{P}_{2} \mathrm{O}_{5}$ [26]. As shown in Figure $4 \mathrm{~b}$, after treatment with UVO for $2 \mathrm{~min}$ and slight plasma, the intensity of the peaks at $2 \mathrm{p}_{3 / 2}$ and $2 \mathrm{p}_{1 / 2}$ decreased and the content of the P element changed from $44.63 \%$ in pristine to $39.51 \%$, which shows that the thinning process worked. Additionally, thinning by this method induced an increase in the content of the oxygen element from $32.2 \%$ to $38.47 \%$, and the intensity of peak at $134 \mathrm{eV}$ increased. Moreover, after $300{ }^{\circ} \mathrm{C}$ annealing in a $\mathrm{N}_{2}$ atmosphere, the peak intensity corresponding to $134 \mathrm{eV}$ decreased, shown in Figure 4c. The value of the calculated relative content of the $\mathrm{P}$ element is $41.5 \%$, which reveals that the oxygen element introduced during the thinning process can be partly reduced by an- 
nealing. Despite oxidation occurring in BP flakes during thinning, the oxidation inversely contributes to the protection of BP [27].
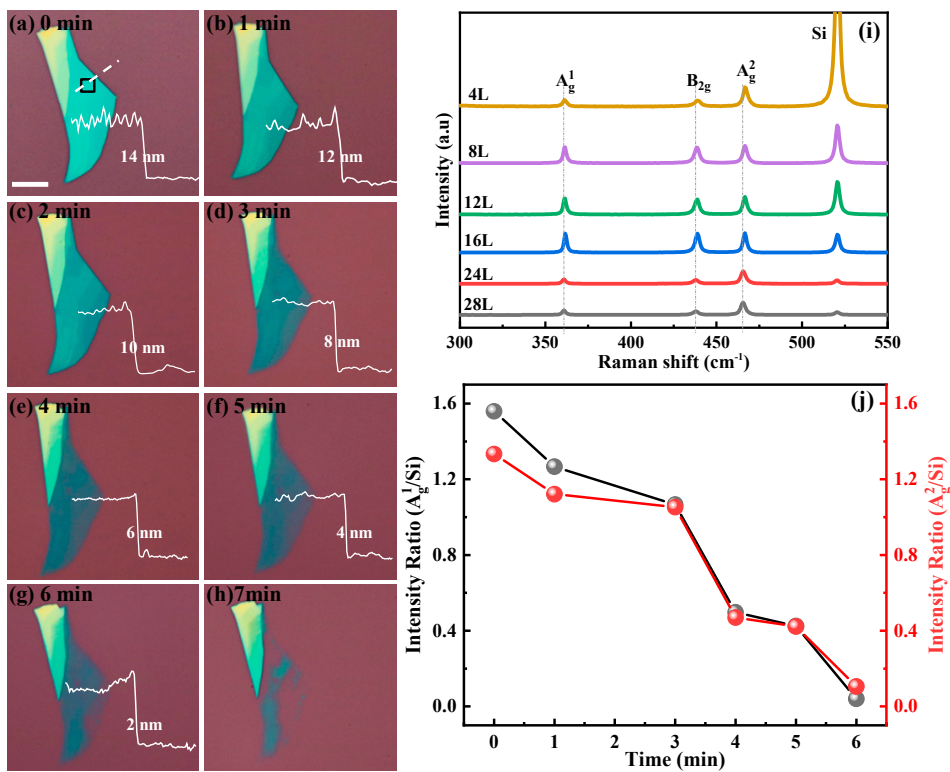

Figure 3. Optical images of mechanically exfoliated BP flakes treated with UV light radiation at different times and $300{ }^{\circ} \mathrm{C}$ annealing in $\mathrm{N}_{2}$ atmosphere $(\mathbf{a}-\mathbf{h})$. The length of the scale bar is $5 \mu \mathrm{m}$. Thinned thicknesses of BP flake as a function of the radiation time are shown as white lines. (i) Raman spectra of the BP flake being treated for various UVO light radiation corresponding to (a-g). (j) Intensity ratio of the $\mathrm{A}^{1}{ }_{\mathrm{g}} / \mathrm{Si}$ and $\mathrm{A}^{2} \mathrm{~g} / \mathrm{Si}$ as functions of the UVO light radiation time.

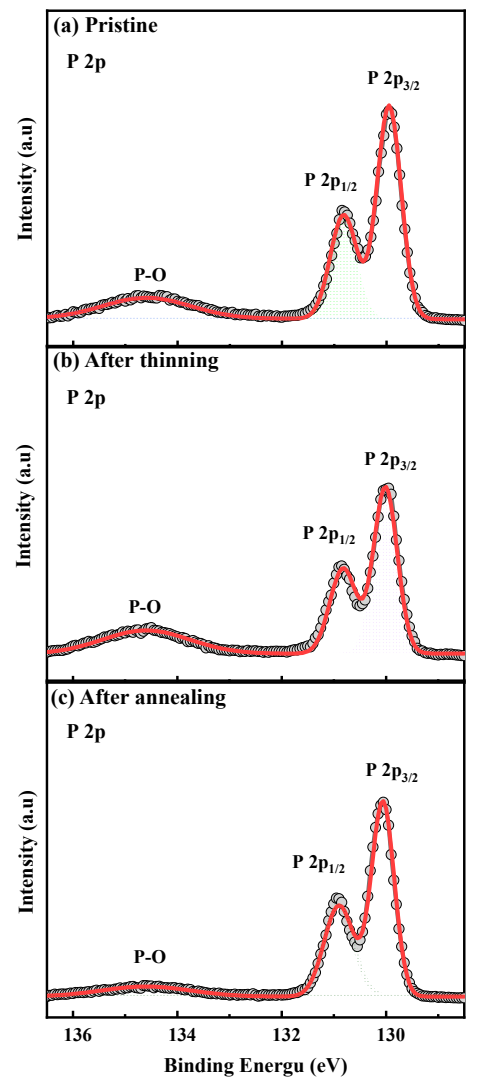

Figure 4. XPS spectra of P 2p. (a) Pristine; (b) after UV light and Ar plasma treatment; (c) after annealing. 


\subsection{Electronic Performance}

To investigate electrical device performance during the thinning process, a $\sim 30 \mathrm{~nm}$ BP-based black-gate field-effect transistor (FET) on $300 \mathrm{~nm} \mathrm{SiO} 2 / \mathrm{Si}$ was fabricated and measured in vacuum conditions at room temperature. Figure $5 \mathrm{a}-\mathrm{c}$ shows source-drain current $\left(\mathrm{I}_{\mathrm{ds}}\right)$-source-drain bias $\left(\mathrm{V}_{\mathrm{ds}}\right)$ characteristics at pristine, after thinning, and after $300{ }^{\circ} \mathrm{C}$ annealing treatment, respectively. Insets are log-scale plots with unit $\sim \mathrm{A}$ on the $\mathrm{y}$-axes. After the thinning process, current modulations decrease and then increase after the annealing process. With variable black-gate $\left(\mathrm{V}_{\mathrm{gs}}\right)$ voltage from $-20 \mathrm{~V}$ to $10 \mathrm{~V}$, current modulations observed throughout the thinning process indicate ohmic contact performance, as confirmed by the linear $\mathrm{I}_{\mathrm{ds}}-\mathrm{V}_{\mathrm{ds}}$ curves. Figure $5 \mathrm{~d}-\mathrm{f}$ displays the transfer characteristics $\left(\mathrm{I}_{\mathrm{ds}}-\mathrm{V}_{\mathrm{gs}}\right)$ of BP FET at pristine, after thinning, and after annealing, with $\mathrm{V}_{\mathrm{ds}}$ changing from $0 \mathrm{~V}$ to $0.5 \mathrm{~V}$, respectively. Insets show optical microscopy images of BP FETs during the thinning process corresponding to Figure $5 \mathrm{a}-\mathrm{c}$, respectively. The changed color of the BP flake indicates decreasing thickness. The device exhibits p-type dominant behaviors, which is in agreement with the previous reports [2,3]. After thinning under slight UVO radiation for $5 \mathrm{~min}$ and $\mathrm{Ar}+$ plasma (step 1) and annealing at $300{ }^{\circ} \mathrm{C}$ in a $\mathrm{N}_{2}$ atmosphere for 1 min (step 2), the transfer curves of BP FET are dramatically changed, shown in Figure 5d-e. After the thinning process, the BP FET shows ambipolarity characteristics in the translated curve. It can be explained by the passivation protection of $\mathrm{P}_{\mathrm{x}} \mathrm{O}_{\mathrm{y}}$ introduced by the thinning process, which can be referred to previous reports on transistors with a weak n-type after BP passivation presentation $[15,28]$. The off-state current at high positive-gate voltage decreases, and the on/off current ratios (the ratio of the $\mathrm{I}_{\mathrm{ds}}$ measured with and without the gate voltage when the $V_{d s}$ is constant) increase significantly from 11 to 281 after steps 1 and 2. This result is due to the effective reduction of the channel thickness, which is consistent with the previous analysis of the AFM images. Further decreases in channel thickness will result in decreases in the interlayer resistance of the $\mathrm{BP}$ films and thus in increases in carrier conduction from the electrical contacts formed on the top surfaces of the BP films [29]. The mobility was estimated with the following formula, $\mu \_$eff $=\mathrm{L} /\left(\mathrm{W} \cdot \mathrm{C} \_\mathrm{g} \cdot \mathrm{V} \_\mathrm{ds}\right) \cdot\left(\mathrm{I} \_\mathrm{ds} / \mathrm{V} \_\mathrm{gs}\right)$, to identify more about the change of $B P$ FET performance under different processes. $L$ and $W$ are the length and width of the device channel, respectively, and $\mathrm{Cg}$ is the oxide capacitance per unit area $\left(11.5 \mathrm{nF} / \mathrm{cm}^{2}\right.$ for $300 \mathrm{~nm} \mathrm{SiO} 2$ ) [30]. After step 1, the thickness of BP as-exfoliated decreased, and a strong interface state formed between $\mathrm{BP}$ and $\mathrm{BP}$ oxide layers that might trap electron conduction, which is consistent with the previous analysis of the XPS [31]. After step 2, thermal annealing reduced the trapping of carriers at interface defects induced by step 1 and was confirmed by the current curves in Figure 5f. The estimated mobility increases from 274 to $492 \mathrm{~cm}^{2} \mathrm{~V}^{-1} \cdot \mathrm{s}^{-1}$ and is accompanied by the threshold voltage shift after thinning. These observations are attributed to p-type doping from atmospheric adsorbates, similar to effects observed with other 2D materials [22,32]. Due to the short time of thinning, the exfoliated material itself is not too thin to significantly enhance the mobility of BP FET. Further work needs to be done to investigate the performance of the device by this method. 

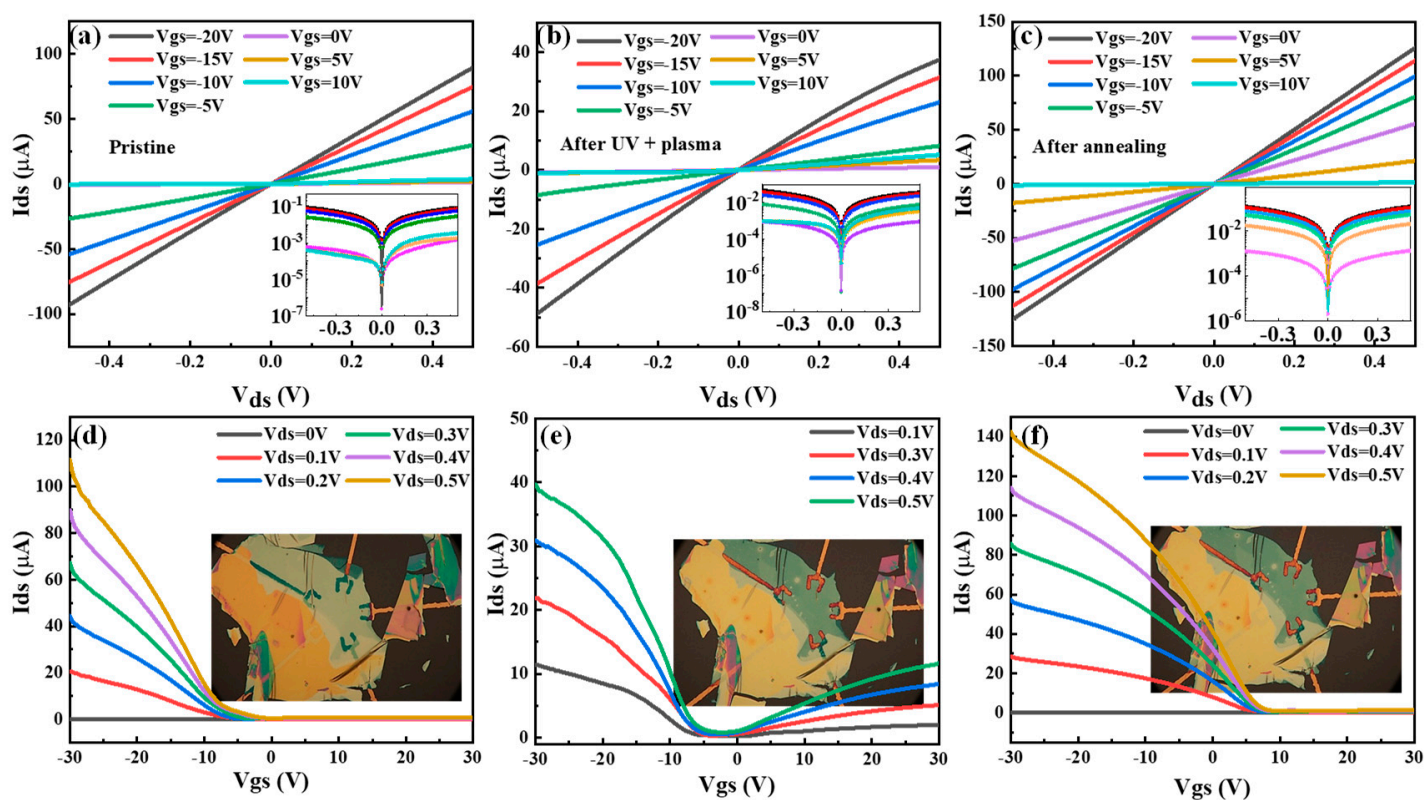

Figure 5. Current performance of BP flakes under different status which were tested at room temperature. $\mathrm{I}_{\mathrm{ds}}-\mathrm{V}_{\mathrm{ds}}$ characteristics of BP FET at pristine (a), after thinning by 5 min light UVO and slight $\mathrm{Ar}^{+}$plasma treatment (b), and after $300{ }^{\circ} \mathrm{C}$ annealing in $\mathrm{N}_{2}$ atmosphere (c), with $\mathrm{V}_{\mathrm{gs}}$ varying from $-20 \mathrm{~V}$ to $10 \mathrm{~V}$. Insets are log-scale plots with unit $\mathrm{A}$ on the $\mathrm{y}$-axes. $\mathrm{I}_{\mathrm{ds}}-\mathrm{V}_{\mathrm{gs}}$ characteristics at pristine $(\mathbf{d})$, after UVO and $\mathrm{Ar}^{+}$plasma treatment (e), and after annealing (f), with $\mathrm{V}_{\mathrm{ds}}$ varying from $0 \mathrm{~V}$ to $0.5 \mathrm{~V}$. The insets are optical microscopy images of fabricated BP FETs under different treatments.

\subsection{Noise Performance}

To further validate the characteristics of the BP thinned by this method, we studied the noise performance of the sample. The same sample was put into a vacuum chamber at room temperature at every step of the experiment. Figure 6a shows the spectra density $\left(\mathrm{SI}^{2}\right)$ under different treatments. Compared with the pristine, there is a slightly stronger noise density that occurred after BP thinning, which indicates impurities or defects on the induced BP. It is clear that the impurities or trap centers due to defects at the BP interface contribute significantly to noise density, which can be proven by XPS analysis of the changes above the P-O peak. Fortunately, it can be seen that the noise density obviously decreased after annealing treatment. Carriers from the impurity or defects we considered decreased during the annealing process, as well as the residues from device fabrication. On the other hand, the increase and decrease in carriers can also be proven by the current amplitude fluctuations, as shown in Figure $6 \mathrm{~b}$. The pristine sample indicates a small amount of fluctuation, but the sample after thinning shows a large one, which shows that the thinning process introduced defects and impurities even though it thinned the BP flakes [33-36]. After annealing, the current fluctuation due to carriers was effectively suppressed, as shown in the inset image, indicating a decrease in the defects or impurities on the BP. Consequently, the annealing process can improve the surface of BP, and this can be easily seen from the current fluctuations. 

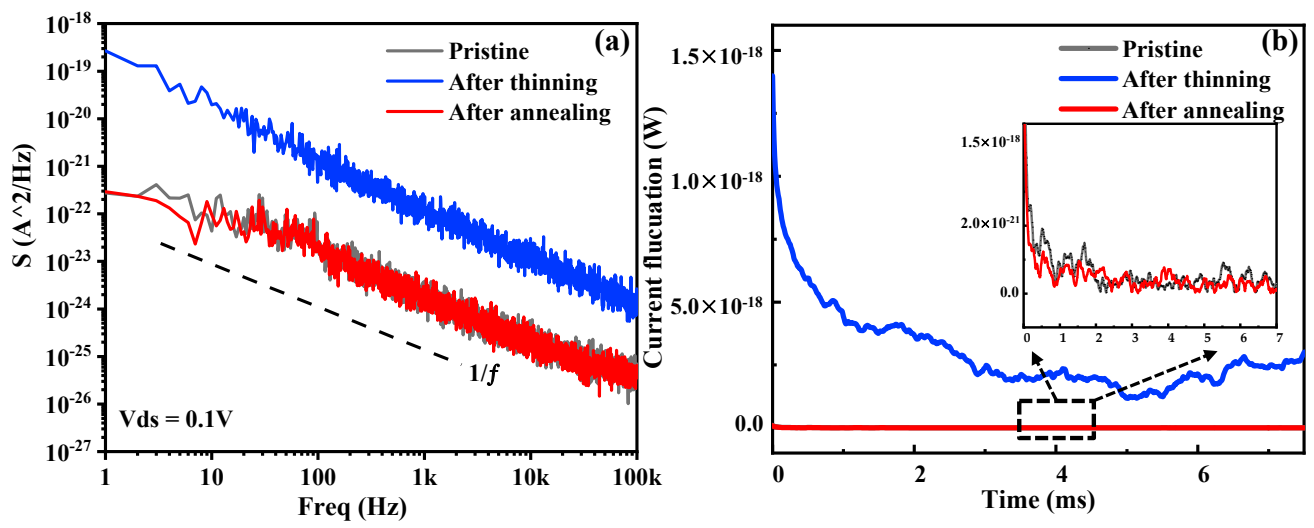

Figure 6. (a) Noise spectral density $\mathrm{S}\left(\mathrm{I}^{2}\right)$ for the BP device under different treatments at room temperature. The source-drain bias was $0.1 \mathrm{~V}$. Note that the $1 / \mathrm{f}$ noise increases after step 1 and decreases after step 2. (b) Current fluctuations in the time domain at the same current values and temperature. Inset shows the current fluctuations between the pristine (black) and the sample after annealing (red).

\section{Conclusions}

As a result, we explored a two-step method of thinning BP flakes with low damage. A slight UVO radiation was used to thin the flakes, and light plasma was induced to remove the residual oxidation of $\mathrm{P}$ on the top surface during thinning process. The flattened surface with low defect was obtained by annealing treatment. The on/off current and mobility of device based on BP indicate improvement after the thinning process. The two-step method provides an effective path to fabricating high-quality BP-based devices with a designed layer thickness.

Supplementary Materials: The following supporting information can be downloaded at https: / / www.mdpi.com/article/10.3390/ma15020615/s1, Figure S1: Survey XPS spectrum of BP flakes.

Author Contributions: Conceptualization, J.F. and Q.L.; formal analysis and investigation, Q.L., X.L. (Xiaoyang Li), D.C., and T.L.; writing—original draft preparation and methodology, J.F., Q.L., and X.L. (Xiaoyang Li); writing-review and editing, H.C., S.W., Y.J., Q.L., and X.L. (Xiangtai Liu); supervision, J.Z. and Y.H. All authors have read and agreed to the published version of the manuscript.

Funding: This research was funded by the Scientific Research Program funded by the Shaanxi Provincial Education Department (Program No. 20JK0909).

Institutional Review Board Statement: Not applicable.

Informed Consent Statement: Not applicable.

Data Availability Statement: The data presented in this study are available on request from the corresponding author.

Acknowledgments: Thanks are due to Xidian University.

Conflicts of Interest: The authors declare no conflict of interest, and the funders had no role in the design of the study; in the collection, analyses, or interpretation of data; in the writing of the manuscript; or in the decision to publish the results.

\section{References}

1. Tran, V.; Soklaski, R.; Liang, Y.; Yang, L. Layer-controlled band gap and anisotropic excitons in few-layer black phosphorus. Phys. Rev. B 2014, 89, 235319. [CrossRef]

2. Li, L.; Yu, Y.; Ye, G.J.; Ge, Q.; Ou, X.; Wu, H.; Feng, D.; Chen, X.H.; Zhang, Y. Black phosphorus field-effect transistors. Nat. Nanotechnol. 2014, 9, 372-377. [CrossRef] [PubMed]

3. Qiao, J.; Kong, X.; Hu, Z.-X.; Yang, F.; Ji, W. High-mobility transport anisotropy and linear dichroism in few-layer black phosphorus. Nat. Commun. 2014, 5, 4475. [CrossRef] 
4. Choi, S.J.; Kim, B.-K.; Lee, T.-H.; Kim, Y.H.; Li, Z.; Pop, E.; Kim, J.-J.; Song, J.H.; Bae, M.-H. Electrical and Thermoelectric Transport by Variable Range Hopping in Thin Black Phosphorus Devices. Nano Lett. 2016, 16, 3969-3975. [CrossRef]

5. Jin, L.; Hu, P.; Wang, Y.; Wu, L.; Qin, K.; Cheng, H.; Wang, S.; Pan, B.; Xin, H.; Zhang, W.; et al. Fast-acting blackphosphorusassisted depression therapy with low toxicity. Adv. Mater. 2020, 32, 1906050. [CrossRef]

6. Li, Z.; Hu, Y.; Fu, Q.; Liu, Y.; Wang, J.; Song, J.; Yang, H. NIR/ROS-responsive black phosphorus QD vesicles as immunoad-juvant carrier for specific cancer photodynamic immunotherapy. Adv. Funct. Mater. 2019, 30, 1905758. [CrossRef]

7. Liu, M.D.; Yu, Y.; Guo, D.K.; Wang, S.B.; Li, C.X.; Gao, F.; Zhang, C.; Xie, B.R.; Zhong, Z.; Zhang, X.Z. Integrationofa Porous Coordination Network and Black Phosphorus Nanosheets Forimproved Photodynamic Therapy of Tumor. Nanoscale 2020, 12, 8890-8897. [CrossRef] [PubMed]

8. Ge, X.; Xia, Z.; Guo, S. Recent Advances on Black Phosphorus for Biomedicine and Biosensing. Adv. Funct. Mater. 2019, 29, 1900318. [CrossRef]

9. Youngblood, N.; Chen, C.; Koester, S.J.; Li, M. Waveguide-integrated black phosphorus photodetector with high responsivity and low dark current. Nat. Photon. 2015, 9, 247-252. [CrossRef]

10. Xu, M.; Gu, Y.; Peng, R.; Youngblood, N.; Li, M. Black phosphorus mid-infrared photodetectors. Appl. Phys. A 2017, 123, 130. [CrossRef]

11. Fan, S.; Qiao, J.; Lai, J.; Hei, H.; Feng, Z.; Zhang, Q.; Zhang, D.; Wu, S.; Hu, X.; Sun, D.; et al. Wet Chemical Method for Black Phosphorus Thinning and Passivation. ACS Appl. Mater. Interfaces 2019, 11, 9213-9222. [CrossRef]

12. Jeong, M.-H.; Kwak, D.-H.; Ra, H.-S.; Lee, A.-Y.; Lee, J.-S. Realizing Long-Term Stability and Thickness Control of Black Phosphorus by Ambient Thermal Treatment. ACS Appl. Mater. Interfaces 2018, 10, 19069-19075. [CrossRef] [PubMed]

13. Clark, N.; Nguyen, L.; Hamer, M.J.; Schedin, F.; Lewis, E.A.; Prestat, E.; Garner, A.; Cao, Y.; Zhu, M.; Kashtiban, R.; et al. Scalable Patterning of Encapsulated Black Phosphorus. Nano Lett. 2018, 18, 5373-5381. [CrossRef]

14. Liu, X.; Chen, K.; Wells, S.A.; Balla, I.; Zhu, J.; Wood, J.D.; Hersam, M.C. Scanning Probe Nanopatterning and Layer-by-Layer Thinning of Black Phosphorus. Adv. Mater. 2017, 29, 1604121. [CrossRef]

15. Robbins, M.C.; Namgung, S.; Oh, S.-H.; Koester, S.J. Cyclical Thinning of Black Phosphorus with High Spatial Resolution for Heterostructure Devices. ACS Appl. Mater. Interfaces 2017, 9, 12654-12662. [CrossRef] [PubMed]

16. Pei, J.; Gai, X.; Yang, J.; Wang, X.; Yu, Z.; Choi, D.-Y.; Luther-Davies, B.; Lu, Y. Producing airstable monolayers of phos-phorene and their defect engineering. Nat. Commun. 2016, 7, 10450. [CrossRef] [PubMed]

17. Sruthi, K.; Taimur, A.; Sivacarendran, B.; Collis, G.E.; Vipul, B.; Igor, A.; Sharath, S.; Madhu, B.; Sumeet, W. Effects of plas-matreatment on the electrical and optoelectronic properties of layered black phosphorus. Appl. Mater. Today 2018, 12, $244-249$.

18. Faraone, G.; Sipala, R.; Mariani, M.; Martella, C.; Bonera, E. Probing the laser ablation of black phosphorus by raman spec-troscopy. J. Phys. Chem. C 2021, 125, 8704-8711. [CrossRef]

19. Lu, W.; Nan, H.; Hong, J.; Chen, Y.; Zhu, C.; Liang, Z.; Ma, X.; Ni, Z.; Jin, C.; Zhang, Z. Plasma assisted fabrication of mon-olayer phosphorene and its Raman characterization. Nano Res. 2014, 7, 853-859. [CrossRef]

20. Kwon, H.; Seo, S.W.; Kim, T.G.; Lee, E.S.; Lanh, P.T.; Yang, S.; Ryu, S.; Kim, J.W. Ultrathin and Flat Layer Black Phosphorus Fabricated by Reactive Oxygen and Water Rinse. ACS Nano 2016, 10, 8723-8731. [CrossRef] [PubMed]

21. Kim, S.; Jung, Y.; Lee, J.-Y.; Lee, G.-H.; Kim, J. In situ thickness control of black phosphorus field-effect transistors via ozone treatment. Nano Res. 2016, 9, 3056-3065. [CrossRef]

22. Wood, J.D.; Wells, S.A.; Jariwala, D.; Chen, K.-S.; Cho, E.; Sangwan, V.K.; Liu, X.; Lauhon, L.; Marks, T.J.; Hersam, M.C. Effective Passivation of Exfoliated Black Phosphorus Transistors against Ambient Degradation. Nano Lett. 2014, 14, 6964-6970. [CrossRef] [PubMed]

23. Island, J.; Steele, G.A.; Van Der Zant, H.S.J.; Castellanos-Gomez, A. Environmental instability of few-layer black phosphorus. 2D Mater. 2015, 2, 011002. [CrossRef]

24. Castellanos-Gomez, A.; Vicarelli, L.; Prada, E.; Island, J.O.; Narasimha-Acharya, K.L.; Blanter, S.I.; Groenendijk, D.J.; Buscema, M.; Steele, G.A.; Alvarez, J.V.; et al. Isolation and characterization of few-layer black phosphorus. 2D Mater. 2014, 1, 025001. [CrossRef]

25. Favron, A.; Gaufrès, E.; Fossard, F.; Phaneuf-L'Heureux, A.-L.; Tang, N.Y.-W.; Levesque, P.; Loiseau, A.; Leonelli, R.; Francoeur, S.; Martel, R. Photooxidation and quantum confinement effects in exfoliated black phosphorus. Nat. Mater. 2015, 14, 826-832. [CrossRef] [PubMed]

26. Zhu, X.; Zhang, T.; Sun, Z.; Chen, H.; Guan, J.; Chen, X.; Ji, H.; Du, P.; Yang, S. Black Phosphorus Revisited: A Missing Metal-Free Elemental Photocatalyst for Visible Light Hydrogen Evolution. Adv. Mater. 2017, 29, 1605776. [CrossRef]

27. Zhou, Q.; Chen, Q.; Tong, Y.; Wang, J. Light-Induced Ambient Degradation of Few-Layer Black Phosphorus: Mechanism and Protection. Angew. Chem. Int. Ed. Eng. 2016, 155, 11437-11441. [CrossRef] [PubMed]

28. Haratipour, N.; Koester, S.J. Ambipolar Black Phosphorus MOSFETs with Record n-Channel Transconductance. IEEE Electron Device Lett. 2015, 37, 103-106. [CrossRef]

29. Jia, J.; Jang, S.K.; Lai, S.; Xu, J.; Choi, Y.J.; Park, J.-H.; Lee, S. Plasma-Treated Thickness-Controlled Two-Dimensional Black Phosphorus and Its Electronic Transport Properties. ACS Nano 2015, 9, 8729-8736. [CrossRef]

30. Yang, S.; Kim, A.; Park, J.; Kwon, H.; Lanh, P.T.; Hong, S.; Kim, K.J.; Kim, J.W. Thermal annealing of black phosphorus for etching and protection. Appl. Surf. Sci. 2018, 457, 773-779. [CrossRef] 
31. Han, C.; Hu, Z.; Carvalho, A.; Guo, N.; Zhang, J.; Hu, F.; Xiang, D.; Wu, J.; Lei, B.; Wang, L.; et al. Oxygen induced strong mobility modulation in few-layer black phosphorus. 2D Mater. 2017, 4, 021007. [CrossRef]

32. Bao, W.; Cai, X.; Kim, D.; Sridhara, K.; Fuhrer, M.S. High mobility ambipolar MoS2 field-effect transistors: Substrate and die-lectric effects. Appl. Phys. Lett. 2013, 102, 042104. [CrossRef]

33. Dutta, P.; Horn, P.M. Low-frequency fluctuations in solids: $1 /$ f noise. Rev. Mod. Phys. 1981, 53, 497. [CrossRef]

34. Balandin, A.A. Low-frequency $1 / \mathrm{f}$ noise in graphene devices. Nat. Nanotechnol. 2013, 8, 549. [CrossRef]

35. Lu, Q.; Yu, L.; Liu, Y.; Zhang, J.; Han, G.; Hao, Y. Low-Noise Mid-Infrared Photodetection in BP/h-BN/Graphene van der Waals Heterojunctions. Materials 2019, 12, 2532. [CrossRef]

36. Zahid Hossain, M.; Rumyantsev, S.; Shur, M.S.; Balandin, A.A. Reduction of $1 / \mathrm{f}$ noise in graphene after electron-beam irra-diation. Appl. Phys. Lett. 2013, 102, 153512. [CrossRef] 